\title{
P38 Mitogen Activated Protein Kinase Regulates Endothelial VCAM-1 Expression at the Post-transcriptional Level
}

\author{
Anneke Pietersma,* Ben C. Tilly,* Matthias Gaestel ,† Netty de J ong,* \\ J ohn C. Lee, $\neq$ J ohan F. Koster,* and Wim Sluiter*,1 \\ *Department of Biochemistry, Cardiovascular Research Institute (COEUR), Erasmus University Rotterdam, \\ Rotterdam, The Netherlands; †Max-Del brück-Centrum für Molekulare Medizin, Berlin, Germany; and \\ ‡Department of Cellular Biochemistry, SmithKline Beecham Pharmaceuticals, King of Prussia, Pennsylvania
}

Received November 22, 1996

The cytokine tumor necrosis factor (TNF) $\alpha$ was found to stimulate the p38 mitogen activated protein (MAP) kinase signalling cascade in human umbilical vein endothelial cells. TNF $\alpha$ increased the activity of the p38 substrate MAP kinase-activated-protein (MAPKAP) kinase 2 and the subsequent phosphorylation of the small heat shock protein Hsp27 about two to three fold. This stimulation was blocked almost completely by the specific p38 MAP kinase inhibitor SB203580. This inhibitor also suppressed the TNF $\alpha$-induced surface expression of the endothelial adhesion molecule vascular cell adhesion molecule (VCAM)-1. In contrast, inhibition of p38 MAP kinase had no effect on the stimulated surface expression of the intercellular cell adhesion molecule (ICAM)-1. VCAM-1 mRNA accumulation induced by TNF $\alpha$ was not affected by SB203580, suggesting that the p38 MAP kinase signalling cascade regulates the endothelial expression of VCAM-1 at the post-transcriptional level. ๑ 1997 Academic Press

Under conditions of cellular stress, such as heat shock, UV radiation and osmotic stimulation, as well as subsequent to cytokine treatment at least two members of the superfamily of mitogen-activated protein (MAP) kinases are rapidly activated. These enzymes, which are distinct from the extra-cellularly regulated kinase (Erk)-1 and Erk2 stimulated by growth factors, are p38 MAP kinase/reactivating kinase (RK) and c-jun amino terminal kinase (J NK)/ stress-activated protein (SAP) kinase. Like Erk1/2 these enzymes are activated through a cascade in-

\footnotetext{
${ }^{1}$ Corresponding author. Department of Biochemistry, Erasmus University Rotterdam, P. O. Box 1738, 3000 DR Rotterdam, The Netherlands. Fax: 3110 4360615. E-mail: sluiter@bcl.fgg.eur.nl.
}

volving several other kinases as well as small GTP binding proteins (F or review see 1-3).

Recently, two homologues of p38 MAP kinase have been identified in human monocytes by the use of a class of pyridinyl imidazoles (4). These drugs inhibit the production of interleukin- $1 \beta$ and tumor necrosis factor (TNF) by stimulated monocytes. The pyridinyl imidazole SB203580 specifically inhibits p38 MAP kinase (5), and the subsequent phosphorylation of its physiological substrate MAP kinase-activated-proteinkinase-2 (MAPKAP kinase-2). Activation of MAPKAP kinase-2 leads to increased phosphorylation of the small heat shock proteins (H sp) H sp25 and Hsp27 $(6,7)$.

TNF $\alpha$ has been demonstrated to stimulate MAPKAP-kinase 2 activity (8) and to increase the phosphorylation of small Hsp in mammalian cells (9). In endothelial cells TNF $\alpha$ induces the expression of vascular cell adhesion molecule-1 (VCAM-1), and increases the expression of the intercellular cell adhesion molecule1 (ICAM-1). The biological functions of these adhesion molecules are distinct. ICAM-1 binds leukocytes via their $\beta 2$ integrins and can therefore serve to recruit both granulocytes and monocytes from the bloodstream to sites of tissue injury, whereas VCAM-1 binds monocytes and lymphocytes expressing the integrins $\alpha 4 \beta 1$ and $\alpha 4 \beta 7$ specifically supporting the recruitment of chronic inflammatory cells $(10,11)$. In this paper we have investigated whether there is a direct connection between the p38 MAP kinase cascade and the expression of the endothelial adhesion molecules. By the use of the inhibitor SB203580 we demonstrate that the expression of VCAM-1, but not ICAM-1, is likely regulated by the p38 MAP kinase at the post-transcriptional level.

\section{MATERIALS AND METHODS}

Cultureand FACS analysis of endothelial cells. Human umbilical vein endothelial cells (HUVEC) were cultured as previously de- 
scribed (12) in M199 (Flow Laboratories) supplemented with $10 \%$ newborn calf serum, $10 \%$ human serum kindly provided by the Red Cross Bloodbank, Rotterdam, The Netherlands, endothelial cell growth factor, $15 \mathrm{U} / \mathrm{ml}$ heparin, $50 \mathrm{U} / \mathrm{ml}$ penicillin, and $5 \mu \mathrm{g} / \mathrm{ml}$ streptomycin, under $95 \%$ air $/ 5 \% \mathrm{CO}_{2}$. Confluent endothelial monolayers were treated as indicated in the legends, either in the presence or absence of SB203580, which was the generous gift of SmithKline Beecham, King of Prussia, USA. Cells were harvested and incubated for $30 \mathrm{~min}$ at $4^{\circ} \mathrm{C}$ with either monoclonal antibody clone IGI1BI (Monosan, Uden, The Netherlands) directed against VCAM-1, or clone MEM 112 (Monosan) directed against ICAM-1, or control mouse I gGlk. The second antibody was a fluorescein isothiocyanate conjugated rabbit anti-mouse $\mathrm{Fab}_{2}$ fragment (Sigma Chemical Corp). Membrane antigen expression was analysed by fluorescence activated cell sorting (FACS) as previously described (13), and is expressed as linear fluorescence intensity (F.I.).

Polymerase chain reaction. Total RNA was isolated from $10^{6} \mathrm{HU}$ VEC stimulated with TNF $\alpha(0-100 \mathrm{U} / \mathrm{ml}$ in complete M199) according to the method of Chomszynski et al. (14). cDNA was produced from $75 \mathrm{ng}$ of each RNA extract by M-MLV reverse transcriptase (Promega) according instructions provided by the manufacturer. Specific oligonucleotide primers (forward primer:5'-CGGGATCCATCCACAAAGCTGCAAGAA-3', and reverse primer:5'-GCGAATTCGCCACCACTCATCTCGATTT-3'), yielding a polymerase chain reaction (PCR) product of 563 base pairs, were synthesized by Eurogentec according to the VCAM-1 CDNA sequence reported by Cybulsky et al (15). CDNA was amplified by 30 cycles with Goldstar DNA polymerase (Eurogentec) in a Perkin Elmer thermocycler 480 in a touch down protocol, in which the annealing temperature was gradually decreased from $72{ }^{\circ} \mathrm{C}$ to $53^{\circ} \mathrm{C}$. Homology of PCR product with the VCAM-1 CDNA was confirmed by sequence analysis.

Northern blot analysis. Total cellular RNA (20 $\mu \mathrm{g})$ was size-fractioned using $1.2 \%$ agarose formaldehyde gel in the presence of 1 $\mu \mathrm{g}$ ethidium bromide. The RNA was transferred onto Hybond and covalently linked by ultraviol et irradiation. Hybridizations were performed at $42{ }^{\circ} \mathrm{C}$ for $18 \mathrm{~h}$ in $50 \%$ deionized formamide, $1 \mathrm{M} \mathrm{NaCl}, 2.5$ $\%$ dextran sulfate, $35 \mu \mathrm{g} / \mathrm{ml}$ denatured fish DNA in $20 \% \mathrm{P}$ buffer (1\% BSA, 1\% polyvinylpyrrolidone, 1\% Ficoll, $250 \mathrm{mM}$ Tris- $\mathrm{HCl}, 0.5 \%$ Na-pyrophosphate, 5\% SDS). The PCR product (approximately 50 ng CDNA) was radiolabeled with $\left[\alpha-{ }^{32} \mathrm{P}\right] \mathrm{dCTP}( \pm 50 \mu \mathrm{Ci}$ per hybridization)by the use of a labelling kit (Amersham). After hybridization, filters were washed with a final stringency of $2 \times$ SSC $(1 \times=150$ $\mathrm{mM} \mathrm{NaCl}, 15 \mathrm{mM} \mathrm{Na}$ citrate), $0.1 \%$ SDS at room temperature. Autoradiograms were quantified by phospho-imaging (Molecular I maging System GS-363, Biorad).

MAPKAP kinase 2 activity assay. HUVEC were stimulated as indicated in the legends and washed three times with ice-cold phosphate buffered saline (PBS). Thereafter, cells were scraped, sedimented and stored at $-80^{\circ} \mathrm{C}$ prior to the assay. The pellet was re dissolved in lysis buffer (0.27 M sucrose, $50 \mathrm{mM} \mathrm{NaF,} 20 \mathrm{mM}$ Trisacetate, $10 \mathrm{mM} \beta$-glycerophosphate, $5 \mathrm{mM}$ pyrophosphate, $1 \mathrm{mM}$ EGTA, $1 \mathrm{mM} \mathrm{Na} \mathrm{VO}_{4}, 0.1 \mathrm{mM}$ EDTA, $1 \mathrm{mM}$ benzamidine, $0.2 \mathrm{mM}$ phenylmethane-sulfonylfluoride, $2 \mu \mathrm{g} / \mathrm{ml}$ leupeptin, $1 \%$ Triton X-100 and $0.1 \% \beta$-mercaptoethanol, $\mathrm{pH}=7.0$ ) and incubated for 15 minutes at $0{ }^{\circ} \mathrm{C}$. Lysates were cleared by centrifugation and the supernatants were incubated with an anti-MAPKAP kinase 2 antiserum over night prior to addition of protein A-Sepharose. One hour later the immunoprecipitates were washed three times with TBS $(20 \mathrm{mM}$ Tris- $\mathrm{HCl}$, $0.154 \mathrm{M} \mathrm{NaCl}, \mathrm{pH}=7.5$ ) containing $50 \mathrm{mM} \mathrm{NaF}, 1 \mathrm{mM} \mathrm{Na}_{3} \mathrm{VO}_{4}$ and $1 \%$ Triton $\mathrm{X}-100$ and finally resuspended in a buffer consisting of 50 $\mathrm{mM}$ Na- $\beta$-glycerophosphate, 4 mM Mg-acetate, 1 mM EDTA, $20 \mu \mathrm{M}$ H7 (Calbiochem), $20 \mu \mathrm{M}$ HA1077 (Calbiochem), $2.5 \mu \mathrm{M}$ protein kinase A inhibitor (Gibco), and $0.4 \mathrm{mg} / \mathrm{ml} \mathrm{Hsp25}$. The reaction was started by the addition of ATP $(0.1 \mathrm{mM}$ ATP containing $2 \mu \mathrm{Ci} \gamma$ ${ }^{32} \mathrm{P}-\mathrm{ATP}$ ) and terminated 10 minutes later by the addition of SDSstopmix. Samples were subjected to SDS-PAGE and radioactivity in the Hsp25-band was quantitated by phospho-imaging as described above.
Hsp27 phosphorylation. HUVEC were washed twice with phosphate-free modified-Earles and incubated in the same medium containing $0.4 \mathrm{mCi} / \mathrm{ml}^{32} \mathrm{PO}_{4}^{3-}$ (Amersham) for $3 \mathrm{~h}$. Thereafter, the cells were stimulated, washed 3 times $\left(150 \mathrm{mM} \mathrm{NaCl}, 20 \mathrm{mM} \mathrm{Na} \mathrm{PO}_{4}\right.$, $\mathrm{pH}=7.4,0^{\circ} \mathrm{C}$ ) and $\mathrm{Hsp} 27$ phosphorylation was determined as described by Cuenda et al. (5). Briefly, after solubilization of the cells (lysis buffer, 10 minutes), the lysates were collected, cleared by centrifugation and protein G-Sepharose-conjugated anti-Hsp27 antibodies (StressGen, Victoria, Canada) were added to the supernatants. After $2 \mathrm{~h}$ of incubation at $0{ }^{\circ} \mathrm{C}$, the beads were centrifuged, washed 3 times with $1 \mathrm{ml}$ lysis buffer containing $0.5 \mathrm{M} \mathrm{NaCl}$ and twice with Iysis buffer, resuspended in sample mix and subjected to SDS-PAGE. Radioactivity in the Hsp27 band was quantitated by phospho-imaging as described above.

\section{RESULTS}

\section{Stimulation of the p38 MAP Kinase Cascade by TNF $\alpha$ in Endothelial Cells}

To study whether the p38 MAP kinase cascade is linked to the TNF $\alpha$ stimulated expression of endothelial leukocyte adhesion molecules, we first analysed the process of activation of p38 MAP kinase by TNF $\alpha$ in HUVEC. For that reason we stimulated these cells by $\mathrm{TNF} \alpha$ and measured the activity of the p38 MAP kinase target MAPKAP kinase 2 as well as the phosphorylation of the MAPKAP kinase-2 target, the small stress protein Hsp27, in these cells (Fig. 1). As demonstrated in Fig. 1a TNF $\alpha$ stimulates MAPKAP kinase2 activity to about three fold in HUVEC. Furthermore, an increased phosphorylation of endogenous Hsp27 in these cells after TNF $\alpha$-treatment could be observed (Fig. 1b). The activation and phosphorylation of these downstream targets of p38 MAP kinase in response to TNF $\alpha$ indicate a TNF $\alpha$-induced activation of p38 MAP kinase. To examine this further, we used the specific p38 MAP kinase inhibitor SB203580. After preincubation of the HUVEC with this inhibitor the TNF $\alpha$-induced stimulation of MAPKAP kinase-2 activity (data not shown) and the phosphorylation of endogenous Hsp27 could be almost completely blocked (Fig. 1b). This finding confirms the notion that TNF $\alpha$ activates the p38 MAP kinase cascade in HUVEC.

\section{Role of p38 MAP Kinase in the Expression of Endothelial Cell Adhesion Molecules}

In parallel to the stimulation of the p38 MAP kinase cascade, TNF $\alpha$ also stimulates the expression of the endothelial leukocyte adhesion molecules VCAM-1 and ICAM-1. At $6 \mathrm{~h}$ after stimulation of HUVEC with TNF $\alpha$ an increased expression of both VCAM-1 and ICAM-1 can be detected by FACS analysis (Fig. 2). To study the involvement of the p38 MAPK cascade in the regulation of VCAM-1 and ICAM-1 expression, we preincubated HUVEC with the p38 MAP kinase inhibitor SB203580. This inhibition of the p38 MAP kinase significantly reduced the expression of VCAM-1 at the surface of the cell (Fig. 2a). In contrast, ICAM-1 expression was not 
A

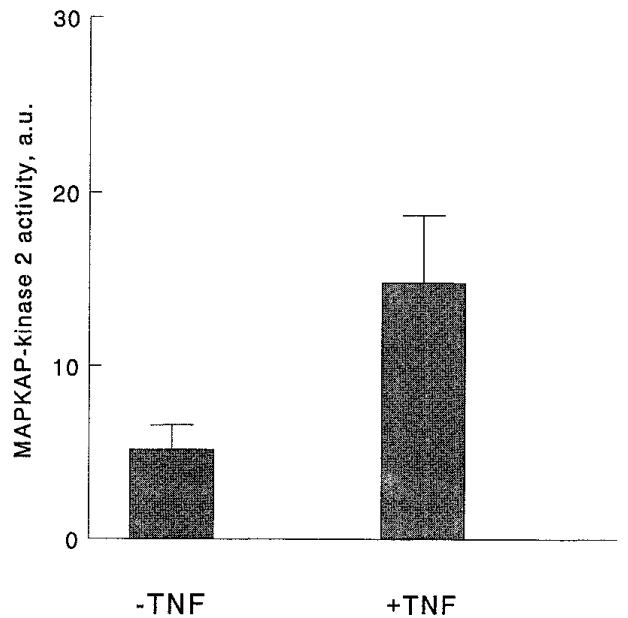

B

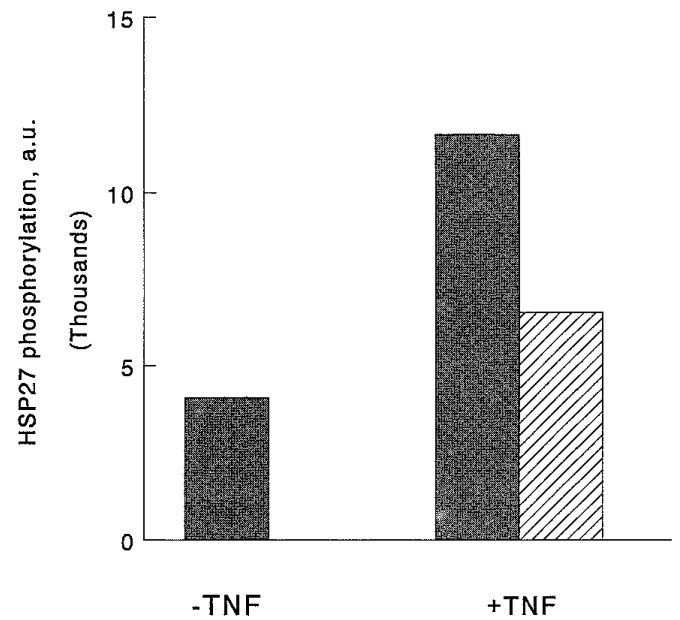

FIG. 1. Activation of MAPKAP kinase 2 activity in endothelial cells stimulated with $100 \mathrm{U} / \mathrm{ml} \mathrm{TNF} \alpha$. After $10 \mathrm{~min}$ of stimulation cells were lysed, and MAPKAP kinase 2 was immuno-precipitated. Enzymatic activity was assessed by $\mathrm{Hsp} 25$ phosphorylation in vitro. Data are presented as mean \pm sem, $n=3$. (b) TNF $\alpha$ stimulated Hsp27 phosphorylation in endothelial cells. ${ }^{32} \mathrm{PO}_{4}^{3-}$ pre-loaded cells were treated with or without $100 \mathrm{U} / \mathrm{ml}$ TNF $\alpha$ for $10 \mathrm{~min}$, in the absence grey bars) or presence (hatched bars) of $20 \mu \mathrm{M}$ SB203580. Hsp27 was immuno-preci pitated and subjected to SDS-PAGE. Radioactivity in the Hsp27 band was quantitated by phospho-imaging. The results are representative of two independent experiments.

affected by inhibition of the p38 MAP kinase in endothelial cells (Fig. 2b).

\section{Evidence for Post-transcriptional Regulation of VCAM-1 Surface Expression by the p38 MAP Kinase Cascade}

To understand the mechanism by which the p38 MAP kinase cascade regulates the VCAM-1 expression in endothelial cells we determined the VCAM-1 mRNAlevel in TNF $\alpha$ stimulated cells in the presence and absence of the p38 MAP kinase inhibitor SB203580. From the results presented in Fig. 3 it can be seen that
SB203580 did not affect the accumulation of VCAM-1 mRNA, which gradually increased after 1 to $6 \mathrm{~h}$ of stimulation with $\operatorname{TNF} \alpha$.

\section{DISCUSSION}

The recently identified p38 MAP kinase signalling cascade is activated under conditions of cellular stress, such as heat shock, hyper osmotic stimulation and after treatment with cytokines (1-3). In the present report we showed that the p38 MAP kinase pathway is functional in HUVEC, since (i) TNF $\alpha$ stimulates the activity of MAPKAP kinase-2 and the subsequent phosphor-
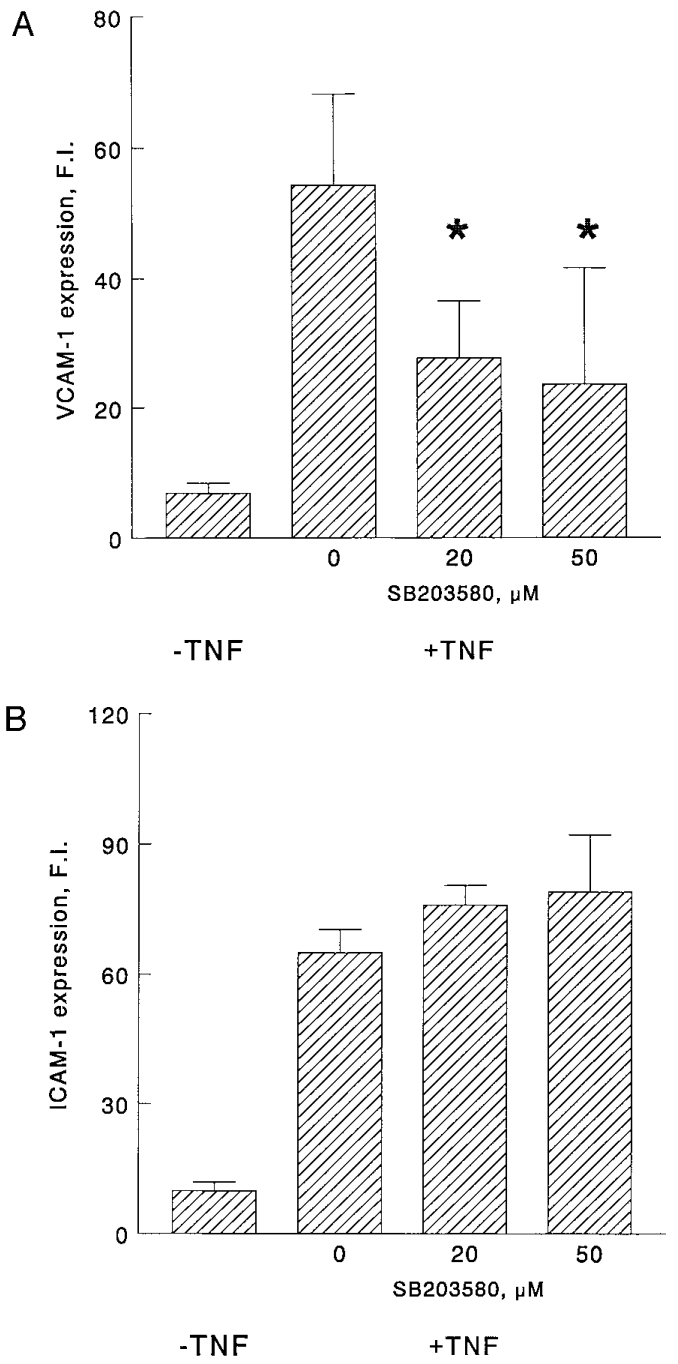

FIG. 2. Effect of SB203580 on the TNF $\alpha$-induced expression of VCAM-1 (a) and ICAM-1 (b). Confluent monolayers of endothelial cells were pretreated with 20 or $50 \mu \mathrm{M}$ SB203580 for $30 \mathrm{~min}$, and subsequently stimulated with $100 \mathrm{U} / \mathrm{ml}$ TNF $\alpha$ for $6 \mathrm{~h}$ also in the presence of SB203580. The expression of VCAM-1 and ICAM-1 was assessed by FACS analysis. The results are expressed as fluorescence intensities (mean \pm sem, $n=3-5$ ). Asterisks indicate a significant difference from the untreated control. (Student's t-test, $p<0.05$ ). 


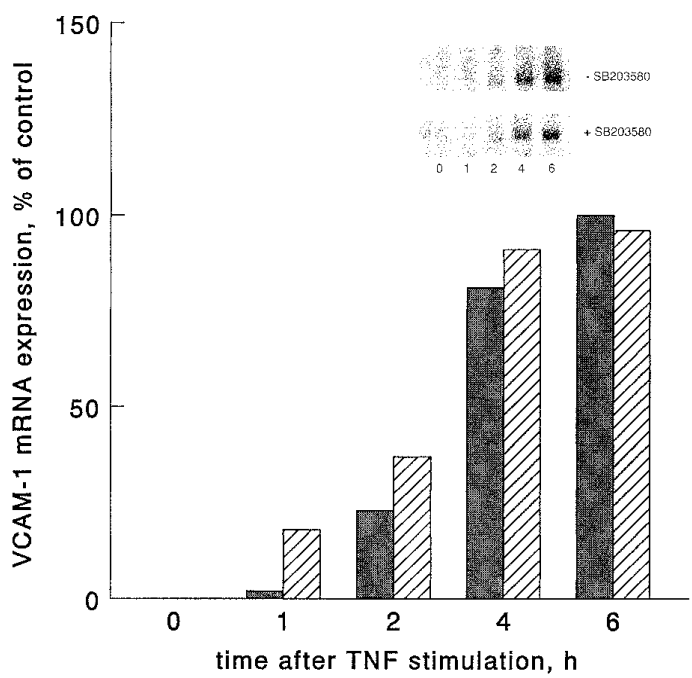

FIG. 3. Time course of the TNF $\alpha$-induced expression of VCAM$1 \mathrm{mRNA}$. After $30 \mathrm{~min}$ pretreatment with $20 \mu \mathrm{M}$ SB203580 or vehicle endothelial cells were stimulated with $100 \mathrm{U} / \mathrm{ml}$ TNF $\alpha$ in the presence (hatched bars) or absence (grey bars) of SB203580. Total RNA was isolated and size-fractioned by denaturing $1.2 \%$ agarose-formaldehyde gel electrophoresis, transferred to nitrocellulose, and hybridized to ${ }^{32} \mathrm{P}$-labeled human VCAM-1-specific CDNA (inset). Data are representative of three indepent experiments.

ylation of $\mathrm{Hsp} 27$ and (ii) TNF $\alpha$-induced stimulation of these downstream components of the p38 MAP kinase cascade is blocked by the p38 MAP kinase inhibitor SB203580. Analysis of the role for p38 MAP kinase in the expression of the endothelial cell adhesion molecules showed that the TNF $\alpha$-induced expression of VCAM-1 but not ICAM-1 is inhibited by the p38 MAP kinase inhibitor. An interesting feature of the regulatory mechanism involved in VCAM-1 surface expression was revealed by Northern blot analysis, since the TNF $\alpha$-induced accumulation of VCAM-1 mRNA clearly showed no difference in the presence or absence of SB203580. Hence, it can be assumed that the p38 MAP kinase pathway regulates VCAM-1 expression at the post-transcriptional level.

Previously, it has been shown that the p38 MAP kinase homologue CSBP regulates the biosynthesis of TNF $\alpha$ by LPS-stimulated human monocytes at the translational level (4). It appears that the regulation of TNF $\alpha$ translation is mediated through an AUUUA repeated motif in the 3'UTR of the TNF $\alpha$ mRNA. Proteins binding to these AUUUA regions may be the target of the CSBP phosphorylation cascade $(16,17)$. However, at present it is unclear whether p38 MAP kinase acts on the translation of VCAM-1 mRNA in a similar fashion, and whether or not MAPKAP kinase-2 and/or phosphorylated Hsp27 are involved in this process.

In the present study we have demonstrated the early activation of the p38 MAP kinase signalling cascade in endothelial cells stimulated with TNF $\alpha$. It seems plausible that the relatively late post-transcriptional regulation of VCAM-1 protein expression requires either a sustained activation of this signalling cascade (18), or the relatively stable phosphorylation of a substrate of the p38 MAP kinase pathway. In this respect it is relevant to indicate that TNF-action in fibroblasts has been shown to involve the inhibition of several protein phosphatases, which would increase the half-life of a putative phosphorylated intermediate (19). It is of note that the complete inhibition of the p38 MAP kinase could only partially decrease VCAM-1 protein expression. This indicates that p38 MAP kinase regulates only part of this post-transcriptional control and that other signalling cascades contribute as well.

The transcriptional regulation of VCAM-1 expression has been studied quite extensively and is likely to involve the assembly of a unique transcription activation complex consisting of the inducible transcription factors NF $\kappa$ B, I RF-1 and constitutive transcription factor Sp-1 (20). However, in the present study we demonstrate for the first time that VCAM-1 protein expression by TNF $\alpha$-stimulated endothelial cells is also regulated at the post-transcriptional level. ICAM-1 expression on the other hand does not seem to depend on p38 MAP kinase activity.

\section{ACKNOWLEDGMENTS}

This study was supported by the Netherlands Heart Foundation Grant 93.124. The authors gratefully acknowledge the help of Dr. $\mathrm{H}$ an van Heugten on the mRNA work and that of Gabriele Schwedersky on the MAPKAP kinase-2 assay. M.G. was supported by the Deutsche Forschungsgemeinschaft (Grant Ga 453/2-3).

\section{REFERENCES}

1. Marshall, C. J . (1995) Cell 80, 179- 185.

2. L'Allemain, G. (1994) Prog. Growth Factor Res. 5, 291- 334.

3. Cano, E., and Mahadevan, L. C. (1995) Trends Biochem. Sci. 20, 117- 122.

4. Lee, J . C., Laydon, J . T., McDonnell, P. C., Gallagher, T. F., Kumar, S., Green, D., McNulty, D., Blumenthal, M.J ., Heys, J . R., Landvatter, S. W., Strickler, J . E., McLaughlin, M. M., Siemens, I. R., Fisher, S. M., Livi, G. P., White, J.R., Adams, J . L., and Young, P. R. (1994) Nature 372, 739- 746.

5. Cuenda, A., Rouse, J ., Doza, Y. N., Meier, R., Cohen, P., Gallagher, T. F., Young, P. R., and Lee, J . C. (1995) FEBS Lett. 364, 229- 233.

6. Stokoe, D., Engel, K., Campbell, D. G., Cohen, P., and Gaestel, M. (1995) FEBS Lett. 313, 307-313.

7. Rouse, J., Cohen, P., Trigon, S., Morange, M., Alonso-Llamazares, A., Zamanillo, D., Hunt, T., and Nebreda, A. R. (1994) Cell 78, 1027- 1037.

8. Engel, K., Ahlers, A., Brach, M. A., Herrmann, F., and Gaestel, M. (1995) J . Cell. Biochem. 57, 321- 330.

9. Arrigo, A. P., and Michel, M. R. (1991) FEBS Lett. 282, 152156.

10. Springer, T. (1995) Cell 76, 301- 314.

11. Elices, M., Osborn, L., Takada, Y., Crouse, C., Luhowskyj, S., Hemler, M., and Lobb, R. (1990) Cell 60, 577-584. 
12. Pietersma, A., de J ong, N., Koster, J . F., and Sluiter, W. (1994) Am J Physiol (Heart Circ Physiol) 39, H874-H879.

13. Pietersma, A., Kofflard, M., de Wit, L. E. A., Stijnen, T., Koster, J.F., Serruys, P.W., and Sluiter, W. (1995) Circulation 91, $1320-1325$.

14. Chomczynski, P., and Sacchi, N. (1987) Anal. Biochem. 162, 156159.

15. Cybulsky, M., Fries, J .W. U., Williams, A. J ., Sultan, P., Eddy, R., Byers, M., Shows, T., Gimbrone, M. A., and Collins, T. (1991) Proc. Natl. Acad. Sci. USA 88, 7859- 7863.
16. Lee, J . C., Laydon, J . T., and White, J . R. (1993) Agents Actions 41, C191-C192.

17. Lee, J . C., and Young, P. R. (1996) J . Leukoc. Biol. 59, 152- 157. 18. Meloche, S., Pagès, G., and Pouysségur, J . (1992) Mol. Biol. Cell 3, 63- 70 .

19. Guy, G. R., Cao, X., Chua, S. P., and Tan, Y. H. (1992) J . Biol. Chem. 267(3), 1846- 1852.

20. Collins, T., Read, M. A., Neish, A. S., Whitley, M. Z., Thanos, D., and Maniatis, T. FASEB J . 9, 899-909. 